\title{
Evaluation of Adenosine Deaminase (Ada) in Tuberculous Pleurisy
}

\author{
S. S. Haque \\ Department of Clinical Biochemistry, Indira Gandhi Institute of Medical Science Patna-14
}

\begin{abstract}
Tuberculosis is a global health problem whose morbidity and mortality is increasing, as one-third of the world population is estimated to be infected with Mycobacterium tuberculosis and eight million new active cases occur annually commonest being pulmonary tuberculosis and is often associated with effusion. Delay in diagnosis and treatment results in poor prognosis. Adenosine deaminase estimation was done by Blake-Berman method. The purpose of this study is to find out the role of ADA levels in differentiation of tuberculous and non-tuberculous exudative pleural effusions of different etiologies. Adenosine deaminase values were compared between tuberculous and non-tuberculous groups and difference in these values was statistically significant $\left({ }^{*} \mathrm{p}<0.01\right.$ for ADA). Adenosine deaminase estimation in pleural fluid has long been taken as a marker for tuberculous pleurisy. ADA levels in non-tuberculous exudative pleural effusions rarely exceeded the cutoff; set for tuberculous disease. The pleural fluid ADA levels were significantly higher in tuberculous exudative pleural effusions when compared with non-tuberculous exudative pleural effusions.
\end{abstract}

Keywords Mycobacterium Tuberculosis, ADA, Pleural Fluid

\section{Introduction}

Tuberculosis (TB) is a serious global health problem, as one-third of the world population is estimated to be infected with Mycobacterium tuberculosis, and eight milion new active cases occur annually[1]. Delay in diagnosis and in the start of effective treatment results in poor prognosis and sequalae in upto $25 \%$ of cases[2]. Conventional methods of diagnosis of tuberculosis were evaluated and all of them were found to have low sensitivity and specificity. Adenosine deaminase(ADA) catalyses the conversion of adenosine to inosine, a stage of purine metabolism. Since 1978, when ADA activity was found to be high in tuberculous pleural exudates[3], ADA has been used in the diagnosis of tuberculous pleural effusions[4-7]; overall, its sensitivity in this role has been $99 \%$ and its specificity $93 \%$ [8]. ADA has two principal isoenzymes, ADA-1 and ADA-2, which have different optimal $\mathrm{pH}$, Michaelis constants and relative substrate specificity patterns[9]. ADA-1 has roughly equal affinities for adenosine and 2'-deoxyadenosine, with a 2'-deoxyadenosine deaminase/ ADA activity ratio of approximately 0.75 ; it is found in many tissues. ADA-2 has much greater affinity for adenosine (2'- deoxyadenosine deaminase/ADA activity ratio approximately 0.25 ), and is found only in macrophages[10], which release it when stimulated by the presence of live micro-organisms in their interior[11]. The high

* Corresponding author:

sshaq2002@yahoo.co.in (S. S. Haque)

Published online at http://journal.sapub.org/ajmms

Copyright (C 2012 Scientific \& Academic Publishing. All Rights Reserved
ADA activities in tuberculous pleural effusions are largely due to ADA-2, in view of which GAKIS and co- workers[12].

Usefulness of adenosine deaminase (ADA) estimation in pleural fluid has been shown as a reliable chemical biomarker specially when there is suspicion of tuberculosis in endemic areas. Sometimes the increase is marked in early stages of the disease and in some other conditions with neutrophillic effusions like in parapneumonic and empyema[13]. Researchers have established that ADA level rarely exceeds the cut-off set for tuberculous effusion in non-tuberculous lymphocytic effusions[14]. The purpose of this study is to find out the role of ADA estimation in differentiation of tuberculous and non-tuberculous exudative pleural effusions.

\section{Materials and Methods}

We evaluated 140 consecutive cases of patients with symptomatic exudative lymphocytic pleural effusion according to Light's criteria (Heffner et al 1997). After the routine procedure of informed consent, a detail history, a through physical examination and routine investigations were done in all the patients. The diagnostic criteria were adopted to label a case as tuberculous were as follows: 1) Presence of acid -fast bacilli. 2) Bacteriological confirmation of presence of Mycobacterium tuberculosis (direct smear or culture or histological finding). 3) Radiological findings consistent with TB.4) a response to antituberculous drugs revealed by an improvement of clinical symptoms and/or a clearing of chest radiograph. 
A malignancy was diagnosed when neoplastic pleural tissue and/or fluid cytology were identified. In infectious disease effusion, patient had a history of fever and pulmonary infiltrate with complete response to antibiotic therapy; pulmonary thromboembolism patients presented with typical dyspnoea of sudden onset,while in pancreatitis the histology is characterized by lymphoplasmocytic infiltration especially around the pancreatic ducts .

Pleural fluid and blood samples were taken at the same time from fasting patients. Both samples were centrifuged for $10 \mathrm{~min}$ at $1,000 \mathrm{xg}$, and the supernatants were used for assay. Pleural biopsies were performed with a COPE needle[15] or ABRAMS needle[16], except when a transudate was suspected.

Adenosine deaminase estimation was done by BlakeBerman method[17] which is comparable with the GiustiGalanti method as is established by a meta-analysis of 2251 cases[18]. Adenosine deaminase Level of more than $40 \mathrm{U} / \mathrm{L}$ is taken as cut-off for tuberculosis, same value was taken by other workers also[19].

\subsection{Statistical Analysis}

Results are expressed as Mean $\pm \mathrm{SD}$. The statistical analyses applied included the standard normal variate test, to analyze the difference between tubercular $(\mathrm{n}=80)$ and non-tubercular $(n=60)$. The statistical significance of differences between means was estimated.

\section{Results}

In our study, 140 samples were thus included between the age group of 14 to 60 years. Male: Female ratio is $3: 1$. Tuberculous group had 80 samples while non-tuberculous group had 60 samples. Non-tuberculous group included different etiologies, namely, malignancy $(n=20)$, infectious diseases $(n=9)$, pancreatitis $(n=12)$ Chronic nonspecific inflammation $(\mathrm{n}=19)$, (Table 1$)$. Out of 80 , only 10 cases $(12.5 \%)$ were confirmed as having tuberculosis by bacteriological confirmation of presence of Mycobacterium tuberculosis

Table 1. Distribution of the Cases According to Accepted Criteria

\begin{tabular}{|c|c|c|}
\hline Group & Disease & Number of Cases \\
\hline \multirow{4}{*}{$\begin{array}{c}\text { Tuberculosis } \\
(\mathrm{n}=80)\end{array}$} & Tuberculosis & 80 \\
\cline { 2 - 3 } $\begin{array}{c}\text { Non-Tuberculosis } \\
(\mathrm{n}=60)\end{array}$ & Malignancy & 20 \\
\cline { 2 - 3 } & $\begin{array}{c}\text { Infectious diseases } \\
\text { Chronic nonspecific }\end{array}$ & 12 \\
\cline { 2 - 3 } & inflammation & 19 \\
\hline
\end{tabular}

In tuberculous group the mean $\pm \mathrm{SD}$ of ADA was $54.50 \pm$ 26.38 while collectively in non-tuberculous group it was $29.28 \pm 16.99$ (Table 2).

Amongst different groups in non-tuberculous disease: in malignant group of mean \pm SD was $17.96 \pm 9.1$, Pancreatitis mean $\pm \mathrm{SD}$ was $19.80 \pm 8.9$ in infectious disease group mean $\pm \mathrm{SD}$ was $13.8 \pm 8.36$, in pulmonary thromboembolism mean $\pm \mathrm{SD}$ was $17.09 \pm 9.66$.

In tuberculous group the mean $\pm \mathrm{SD}$ of $\mathrm{ADA}-2$ was $63.34 \pm 19.06$ while collectively in non-tuberculous group it was 31.99 \pm 9.9 (Table 2).Amongst different groups in non-tuberculous disease: in malignant group mean $\pm \mathrm{SD}$ was $20.97 \pm 8.3$, Pancreatitis mean \pm SD was $43.8 \pm 1.9$ in infectious disease group mean \pm SD was $17.3 \pm 8.1$, in pulmonary thromboembolism mean \pm SD was $29.3 \pm 11.3$

Table 2. ADA with Mean \pm SD in Different Groups

\begin{tabular}{|c|c|c|c|}
\hline Aetiology & $\mathrm{ADA}$ & ADA-2 & $\begin{array}{c}\text { p-value of } \\
\text { ADA groups }\end{array}$ \\
\hline $\begin{array}{c}\text { Tuberculosis } \\
\text { Non-Tuberculous }\end{array}$ & $54.50 \pm 26.38$ & $63.34 \pm 19.06$ & \multirow{6}{*}{$\begin{array}{c}0.0006 \\
(\mathrm{p}<0.01)^{*} \\
\text { Between tu- } \\
\text { berculous and } \\
\text { overall of non- } \\
\text { tuberculous }\end{array}$} \\
\hline Over all & $29.28 \pm 16.99$ & $31.99 \pm 9.9$ & \\
\hline Malignancy & $17.96 \pm 9.1$ & $20.97 \pm 8.3$ & \\
\hline Pancreatitis & $19.8 \pm 8.9$ & $43.8 \pm 14.9$ & \\
\hline Infectious diseases & $13.8 \pm 8.36$ & $17.3 \pm 8.1$ & \\
\hline $\begin{array}{c}\text { Pulmonary } \\
\text { Thromboembolism }\end{array}$ & $17.09 \pm 9.66$ & $29.3 \pm 11.3$ & \\
\hline
\end{tabular}

Adenosine deaminase level in all 80 samples of tuberculous group was above diagnostic cut-off $(40 \mathrm{U} / \mathrm{L})$; while in non-tuberculous group only few sample was above cutoff.

Adenosine deaminase values were compared between tuberculous and non-tuberculous groups and difference in these values was statistically significant. On comparing the ADA values amongst different non-tubercular groups; the difference was statistically significant between over all of non tuberculous and malignant group $\left({ }^{*} \mathrm{p}<0.01\right.$ for ADA) and pancreatits group and ADA-2 also shows statistically significant between over all of non tuberculous and tuberculous group (Table 2).

\section{Discussion}

Exudative lymphocytic pleural effusions are commonly encountered in clinical practice but they often constitute difficult diagnostic problems. The two most common causes are malignancy and tuberculous effusions[20]. For tuberculosis, the limitation of diagnostic tests are few positive staining and culture from pleural fluid, and time consuming for identification[21]. Adenosine deaminase is considered an indicator of cell-mediated immunity and is found mainly in T lymphocytes and macrophages[22]. Since the initial proposal of Piras et al, many studies have confirmed the utility of ADA for diagnosis of tuberculous pleural effusion[23-26] though some have questioned its diagnostic value[27-30].

In patients with tuberculous exudative pleural effusion, neutrophils predominate in the early stages of the disease, while abundant mononuclear cells is a classical finding later and is believed to be due to the proliferation and differentiation of lymphocytes which release lymphokines, which in turn activate macrophages for an enhanced bactericidal activity[31,32]. Even pleural fluid cytology takes a back seat 
while investigating the cause of an exudative pleural effusion, and is usually just evidence supporting our final diagnosis.

Adenosine deaminase estimation in pleural fluid has long been taken as a marker for tuberculous pleurisy. Levels above $40 \mathrm{U} / \mathrm{L}$ indicate pleural tuberculosis with sensitivity 81 to $100 \%$ and specificity 83 to $100 \%[33-35$ ], while some other workers have observed that this cut-off indicates a still higher sensitivity of $90-100 \%$ and specificity of 89 $100 \%[36-41]$. There are several known isoforms of ADA, which arise from different gene loci[42] out of which ADA-1 is found in all cells including lymphocytes and monocytes, while ADA-2 is found exclusively in monocytes[43]. ADA2 isoform is the one raised in tuberculous pleurisy, accounting for almost $88 \%$ of total ADA activity. Rise in ADA-1 activity is more commonly associated with pyogenic bacterial infection of the pleural cavity, contributing to a median $70 \%$ of total ADA activity[44]. However there is no clear advantage of using the ADA-2 over the total ADA activity in clinical practice[45]. The total ADA activity assay is in fact preferred for its rapid turnover and low cost.

ADA levels can play a very significant role in differentiating cases of exudative pleural effusion into tuberculous and non-tuberculous. Thus ADA can be used for ruling out suspected cases of tuberculosis and can be a very effective screening test. India has a high prevalence of tuberculosis and the sensitivity and specificity of this test will be high in this population. Therefore ADA estimation being a simple, low cost, rapid and non-invasive test should become an integral part of the diagnostic work up of exudative pleural effusions in suspected cases of tuberculosis

\section{Conclusions}

In conclusion, we believe that high ADA activity in tuberculous effusions is due mainly to an increase in ADA-2 activity, and is therefore probably produced by monocytes/macrophages. In this study, ADA levels in non- tuberculous exudative pleural effusions rarely exceeded the cutoff; set for tuberculous disease. The pleural fluid ADA levels were significantly higher in tuberculous exudative pleural effusions when compared with non-tuberculous exudative pleural effusions. Adenosine deaminase level of less than $40 \mathrm{U} / \mathrm{L}$ practically excludes the tubercular etiology in exudative pleural effusion cases and thus may be useful in differentiating tuberculous etiology from others in exudative pleural effusion.

\section{REFERENCES}

[1] World Health Organization.Global Tuberculosis Control: Surveillance, Planning, Financing. WHO Report 2004. Geneva, Switzerland

[2] Tandon P N, Neurotuberculosis: Clinical aspects. Neurology in Tripica. Chopra J S and Sawhney I.M.S. ed Churchill Li- vingstone Ltd.;1999.358-89

[3] Gecia-monco J C CNS Tuberculosis. Neurologic clinics. Marra C.M. ed.; 1999. 17(4):737-60

[4] Piras MA, Gakis C, Budroni M, Andreoni G. Adenosine deaminase activity in pleural effusions: an aid to differential diagnosis. Br Med J 1978; 2: 1751-1752

[5] Ocaña I, Martínez Vázquez JM, Segura RM, Fernández de Sevilla T, Capdevila JA. Adenosine deaminase in pleural fluids: test for diagnosis of tuberculous pleural effusion. Chest 1983; 84: 51-53

[6] Pettersson T, Ojala K, Weber TH. Adenosine deaminase in the diagnosis of pleural effusion. Acta Med Scand 1984; 215: 299-304

[7] Fontán J, Verea H, Pérez J, Domínguez L, Martín MT, Montero MC. Diagnostic value of simultaneous determination of pleural adenosine deaminase and pleural lysozyme/serum lysozyme ratio in pleural effusions. Chest 1988; 93: 303-307

[8] Valdés L, San José E, Alvarez D, et al. Diagnosis of tuberculous pleurisy using the biologic parameters adenosine deaminase, lysozyme and interferon-gamma. Chest 1993; 103: $458-465$

[9] Ena J, Valls V, Pérez de Oteyza C, Enríquez de Salamanca R. Utilidad y limitaciones de la adenosina desaminasa en el diagnóstico de la pleuresía tuberculosa: studio metaanalítico. Med Clin (Barc) 1990; 95: 333-335

[10] Hirschhorn R, Ratech H. Isoenzymes of adenosine deaminase. In: Ratazzi MC, Scandalia JG, Whitt GS, eds. Isoenzymes: Current Topics in Biological and Medical Research. New York, Alan R. Liss, 1980; pp. 132-157

[11] Zuckerman SH, Olson JM, Douglas SD. Adenosine deaminase activity during in vitro culture of human peripheral blood monocytes and pulmonary alveolar macrophages. Exp Cell Res 1980; 129: 281-287

[12] Gakis C, Calia G, Naitana A, Pirino D, Serru G. Serum adenosine deaminase activity in HIV positive subjects: a hypothesis on the significance of ADA-2. Panminerva Med 1989; 31: 107-113

[13] Gakis C, Calia GM, Naitana AGV, Ortu AR, Contu A. Serum and pleural adenosine deaminase activity: correct interpretation of the findings. Chest 1991; 99: 1555-1556

[14] Burgess LJ, Maritz FJ, Le Roux I, Taljaard JJ. Combined use of pleural adenosine deaminase with lymphocyte/ neutrophil ratio. Increased specificity for the diagnosis of tuberculous pleuritis. Chest 1996; 109(2):414-419

[15] Lee YC, Rogers JT, Rodriguez RM, Miller KD, Light RW. Adenosine deaminase levels in nontuberculous lymphocytic pleural effusions. Chest 2001; 120(2):356-361

[16] Cope C. New pleural biopsy needle. J Am Med Assoc 1958; 167: $1107-1108$

[17] Abrams LD. New inventions: a pleural biopsy punch. Lancet $1958 ; 1: 30-31$

[18] Blake J, Berman P. The use of adenosine deaminase assays in the diagnosis of tuberculosis. S Afr Med J 1982;62(1):19-21 
[19] Banales JL, Pineda PR, Fitzgerald JM, Rubio H, Selman M, Salazar-Lezama M. Adenosine deaminase in the diagnosis of tuberculous pleural effusions.A report of 218 patients and review of the literature. Chest 1991;99(2):355-357

[20] Jimenez Castro D, Diaz Nuevo G, Perez-Rodriguez E, Light RW. Diagnostic value of adenosine deaminase in nontuberculous lymphocytic pleural effusions. Eur Respir J 2003; 21(2):220-224

[21] Kataria YP, Khurshid I. Adenosine deaminase in the diagnosis of tuberculous pleural effusion. Chest 2001; 120(2): 334-336

[22] Leibowitz S, Kennedy L, Lessof MH. The tuberculin reaction in the pleural cavity and its suppression by antilymphocyte serum. Br J Exp Pathol 1973;54(2):152- 162

[23] Ribera E, Martinez-Vazquez JM, Ocana I, Ruiz I, Segura RM, Encabo G, Pascual C. [Gamma interferon and adenosine deaminase in pleuritis]. Med Clin (Barc) 1990; 94(10): 364-367

[24] Valdes L, San Jose E, Alvarez D, Sarandeses A, Pose A, Chomon B, Alvarez-Dobano JM, et al. Diagnosis of tuberculous pleurisy using the biologic parameters adenosine deaminase, lysozyme, and interferon gamma. Chest 1993;103(2):458-465

[25] Muranishi H, Nakashima M, Hirano H, Saitoh T, Takahashi H, Tanaka K, Miyazaki M, et al. Simultaneous measurements of adenosine deaminase activity and tuberculostearic acid in pleural effusions for the diagnosis of tuberculous pleuritis. Intern Med 1992;31(6):752- 755

[26] Valdes L, San Jose E, Alvarez D, Sarandeses A, Pose A, Chomon B, Alvarez-Dobano JM, et al. Diagnosis of tuber- culous pleurisy using the biologic parameters adenosine deaminase, lysozyme, and interferon gamma. Chest 1993; 103(2):458-465

[27] Roth BJ. Searching for tuberculosis in the pleural space. Chest 1999; 116(1):3-5

[28] Gilhotra R, Sehgal S, Jindal SK. Pleural biopsy and adenosine deaminase enzyme activity in effusions of different aetiologies. Lung India. 1989;3:122-4

[29] Valdes L, Alvarez D, San Jose E, Penela P, Valle JM, Garcia-Pazos JM, Suarez J, et al. Tuberculous pleurisy: a study of 254 patients. Arch Intern Med. 1998;158(18):2017-2021

[30] Ungerer JP, Oosthuizen HM, Retief JH, Bissbort SH. Significance of adenosine deaminase activity and its isoenzymes in tuberculous effusions. Chest 1994;106(1):33- 37

[31] Burgess LJ, Maritz FJ, Le Roux I, Taljaard JJ. Use of adenosine deaminase as a diagnostic tool for tuberculous pleurisy. Thorax 1995;50(6):672-674

[32] Hirschhorn R, Ratech H. Isozymes of adenosine deaminase. Isozymes Curr Top Biol Med Res 1980;4(131-157

[33] Ungerer JP, Oosthuizen HM, Bissbort SH, Vermaak WJ. Serum adenosine deaminase: isoenzymes and diagnostic application. Clin Chem 1992;38(7):13221326

[34] Laniado-Laborin R. Adenosine deaminase in the diagnosis of tuberculous pleural effusion: is it really an ideal test? A word of caution. Chest 2005; 127(2):417-418. 84

[35] Kataria YP, Khurshid I. Adenosine deaminase in the diagnosis of tuberculous pleural effusion. Chest 2001; 120(2): 334-336 